\title{
Preface to the special issue on diverse applications of tungsten and related metals
}

\author{
Cheng Zhong ${ }^{1,2}$
}

Published online: 23 June 2021

(c) The Nonferrous Metals Society of China 2021

Tungsten (W) is an exceptionally strong refractory metal, which is an important chemical element used in lamp filaments and in steel to increase hardness and strength. Recently, tungsten and related metals, including molybdenum, cobalt, vanadium, tantalum, niobium, rhenium, zirconium, hafnium as well as their alloys and compounds, are also found to be effective in preparing novel energy storage materials. The present issue consists of nine contributions with six review papers and three original research articles, covering the application of tungsten-related metals in energy storage materials, steels, etc.

The special topic focuses on the diverse applications of tungsten-related metals. First, Wang et al. reviewed the role of tungsten-related elements for improving the electrochemical performances of cathode materials in lithiumion batteries. He et al. summarized modification strategies of $\mathrm{Li}_{7} \mathrm{La}_{3} \mathrm{Zr}_{2} \mathrm{O}_{12}$ ceramic electrolyte for high-performance solid-state batteries. Zhang et al. then reported the progress and perspectiveof vanadium-based cathode materials for lithiumionbatteries. Chen et al. also summarized recent developments of vanadium-based cathode for rechargeable zinc-ion batteries. In the review of Wang et al., recent advances in the recovery of transition metals from spent HDS catalysts were highlighted. Sun et al. introduced the effect of molybdenum on localized corrosion resistance of stainless steels. Besides, in the research papers, Luo et al. prepared two-dimensional molybdenum trioxide nanosheet clusters for enhanced surface Li-ions storage. Chen et al. proposed tungsten and arsenic substance flows analysis of

Cheng Zhong

cheng.zhong@tju.edu.cn

$1 \quad$ Key Laboratory of Advanced Ceramics and Machining Technology (Ministry of Education), School of Materials Science and Engineering, Tianjin University, Tianjin 300072, China

2 Tianjin Key Laboratory of Composite and Functional Materials, School of Materials Science and Engineering, Tianjin University, Tianjin 300072, China a hydrometallurgical process for tungsten extracting from wolframite. Besides, Liu et al. analyzed crack in Ti-6Al-4V alloy produced by selective laser melting.

I hope that the special topic could provide insights into diverse applications of tungsten-related metals for the readers and promote more creative researches. More contributions in tungsten and related materials are welcome to be published in the journal Tungsten. Finally, I would like to appreciate all the authors, reviewers, editors, and publishing staff for their great efforts that enable the successful publication of the special issue.

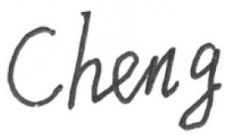<smiles>CCCCCCCCCCCCC</smiles>

Dr. Cheng Zhong

2021.5.20

Publisher's Note Springer Nature remains neutral with regard to jurisdictional claims in published maps and institutional affiliations

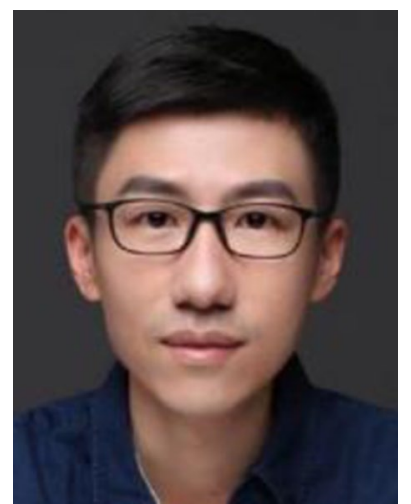

Dr. Cheng Zhong received his $\mathrm{BSc}$ and Ph.D. in Materials Science from Fudan University in 2004 and 2009, respectively. He is now a professor in School of Materials Science and Engineering at Tianjin University, and a board committee member of the International Academy of Electrochemical Energy Science. Prior to joining Tianjin University, he worked as an associate professor in the Department of Materials Science and Engineering at Shanghai Jiao Tong University. Dr. Zhong received the support by the National Science Foundation for Excellent Young Scholars, and he is also the winner of the National "Ten Thousand Plan" 
Youth Talent. He serves as an editorial member of Tungsten, and associate editor of Carbon Energy and Frontiers in Chemistry. His recent research interests focus on electrochemical metallurgy and battery electrochemistry. 